\title{
Mechanisms of partial plant resistance to diamondback moth (Plutella xylostella) in brassicas
}

Article

Accepted Version

Hariprasad, K. V. and van Emden, H. F. (2010) Mechanisms of partial plant resistance to diamondback moth (Plutella xylostella) in brassicas. International Journal of Pest Management, 56 (1). pp. 15-22. ISSN 0967-0874 doi: https://doi.org/10.1080/09670870902980834 Available at https://centaur.reading.ac.uk/17508/

It is advisable to refer to the publisher's version if you intend to cite from the work. See Guidance on citing.

To link to this article DOI: http://dx.doi.org/10.1080/09670870902980834

Publisher: Taylor \& Francis

All outputs in CentAUR are protected by Intellectual Property Rights law, including copyright law. Copyright and IPR is retained by the creators or other copyright holders. Terms and conditions for use of this material are defined in the End User Agreement.

www.reading.ac.uk/centaur 
Central Archive at the University of Reading

Reading's research outputs online 
Mechanisms of partial plant resistance to diamondback moth (Plutella xylostella) in brassicas

\section{KARNAM V. HARIPRASAD ${ }^{1}$ and HELMUT F. VAN EMDEN}

School of Biological Sciences, University of Reading, Whiteknights, Reading, RG6

6AS, UK. Tel: +44 (0)118 3788493; Fax: +44 (0)118 9352421; email:

h.f.vanemden@ reading.ac.uk

${ }^{1}$ Now at: Department of Entomology, S. V. Agricultural College, Tirupati 517502 ,

Chittoor District, Andhra Pradesh, India. Tel: +91 8772249155; Fax: +91 877

2248001; email: kvhp@ hotmail.com

Corresponding author. Email: h.f.vanemden@reading.ac.uk 
Running title: Partial plant resistance to diamondback moth

\title{
Mechanisms of partial plant resistance to diamondback moth (Plutella xylostella) in brassicas
}

\section{K.V. HARIPRASAD ${ }^{1}$ and H. F. VAN EMDEN}

School of Biological Sciences, University of Reading, Whiteknights, Reading, RG6 6AS, UK.

\footnotetext{
${ }^{1}$ Now at: Department of Entomology, S. V. Agricultural College, Tirupati 517 502, Chittoor District, Andhra Pradesh, India.
}

\begin{abstract}
Artificial diet studies were used to differentiate physical and chemical mechanisms affecting the suitability to diamondback moth (Plutella xylostella L.) of 10 food substrates obtained by growing five brassicas in the glasshouse or field and measuring the pest's performance on either leaf discs or diet incorporating leaf powders. Leaves of Chinese cabbage and the cabbage cultivar 'Minicole' were respectively the most and least suitable leaves for the insect, but this ranking was reversed on artificial diet. Leaves of glasshouse-grown plants were more suitable than those of plants grown in the fields. Differences in the suitability of leaves to diamondback moth appeared largely determined by leaf toughness and surface wax load. Concentrations of individual glucosinolates in the brassicas probably acted as phagostimulants to
\end{abstract}


increase their intrinsic susceptibility to diamondback moth, but the impact of the physical factors appeared more important.

Keywords: Diamondback moth, Plutella xylostella , brassica, host plant resistance, leaf toughness, surface waxes, glucosinolates

Correspondence: H. F. van Emden, School of Biological Sciences, University of Reading, Whiteknights, Reading, RG6 6AS, UK. Tel: +44 (0)118 3788493; Fax: +44

(0)118 9352421; email: h.f.vanemden@ reading.ac.uk

\section{Introduction}

Diamondback moth or DBM, Plutella xylostella (L.) (Lepidoptera: Plutellidae), is a notorious insect pest of brassica crops and has gained a world wide reputation as one the few insects to have developed resistance to Bt as a spray formulation, Trichoplusia ni Hübner (Lepidoptera: Noctuidae) being another (Tabashnik et al. 1990, Janmaat 2007). Partial host plant resistance could be used as one key component of IPM of this insect pest. However, to develop cultivars with durable partial resistance to DBM, it is important to understand the mechanisms underlying any reduced susceptibility. Though there have been numerous reports of host plant resistance to DBM (Abro and Wright 1989, Dickson and Eckenrode 1975, 1980, Eigenbrode et al. 1991, Eigenbrode and Shelton 1990, Lin et al. 1983, 1984, Rudder and Brett 1967. Schuler and van Emden 2000, Stoner 1990, Verkerk and Wright 1994), very few have focussed on physical or chemical mechanisms except the papers 
from Eigenbrode's laboratory on the non-acceptance by DBM neonate larvae of glossy lines of brassicas. These papers report that the mechanism of resistance on glossy lines was mainly physical. The leaf wax load and crystalline density accounted for $69 \%$ of the variation in the larval survival on glossy lines. When polar and nonpolar extracts from glossy lines were added to artificial diet, no larval mortality was observed indicating no antibiosis as a result of plant chemistry. It is, however, thought that the resistance shown by some non-glossy brassica cultivars stems from the interaction of more than one type and mechanism of resistance (Verkerk and Wright 1996a,b).

The present study sought leads to the mechanisms of partial resistance of DBM in some non-glossy brassicas by comparing the insect growth responses on leaf discs with those on artificial diet (incorporated with freeze dried leaf material from different brassicas). Artificial diet studies have previously been employed to distinguish between physical or chemical factors affecting host suitability for insects (e.g. Berdegue and Trumble 1996). The other principle feature of the study was the comparison of suitability to DBM of the same brassicas grown in the glasshouse and in the field. Thus, with five brassicas, glasshouse or field conditions and leaves or an artificial diet with leaf powder incorporated, data were taken from 20 potentially different food substrates for the insect.

\section{Materials and methods}

\subsection{Plant cultivars}

Three cultivars of Brassica oleracea L. var. capitata were used: Red Drumhead (RDH, a red cabbage), Offenham Compacta (OC, a green cabbage) and Minicole 
(MIN, another green cabbage). Additionally the Chinese cabbage Wong Bok (CHC) was used. This is B. rapa pekinensis (Loureiro) Hanelt, and was included because it is known to be highly susceptible to DBM (Schuler and van Emden 2000).

\subsection{Glasshouse-grown plants}

The glasshouse had a $14 \mathrm{~h}$ day: $10 \mathrm{~h}$ night regime, and was set to maintain a minimum temperature of $25 \pm 2{ }^{\circ} \mathrm{C}$. Seeds were sown in trays containing John Innes No.2 compost, and two weeks after germination the seedlings were potted singly into 90 mm diameter pots and watered daily. Pirimicarb, a selective aphicide, was applied frequently at $0.50 \mathrm{~g}$ a.i. $\mathrm{1}^{-1}$ to keep the plants free of aphids. Plants of similar physiological age were selected for glasshouse experiments ( 7 to 8 weeks old during spring and summer; 8 to 9 weeks old during autumn and winter).

\subsection{Field-grown plants}

When the seedlings were 2 weeks old, they were planted in the field at the University's farm at Sonning, Berkshire with $0.5 \mathrm{~m}$ spacing between the plants and $1 \mathrm{~m}$ spacing between the rows, with the plots of the different brassicas arranged in a randomised block design. The date of transplanting was taken as the base date for recording the age of the plants. Eighty $\mathrm{kg} \mathrm{ha}^{-1}$ of potassium sulphate $\left(50 \% \mathrm{~K}_{2} 0\right)$ was applied as a basal dose to the soil (MAFF 1994). Plants were watered and weeded regularly and kept free of insect pests other than DBM. Physiologically similar aged plants to those used in the glasshouse experiments were selected in the field for 
measuring the performance of DBM (6 -7 weeks old during spring and summer; 7 - 8 weeks old during autumn and winter).

\subsection{Performance of DBM on the different brassicas on leaf discs}

These experiments were carried out in the laboratory at normal room temperature, i.e. approximately $25^{\circ} \mathrm{C}$. Larval fresh weight $(\mathrm{mg})$ at 5 days old (by which time most of the larvae were in the final instar), larval duration (days) and per cent survival of larvae was measured. For calculating the intrinsic rate of increase $\left(r_{m}\right)$, the survival value used was survival to the adult stage. To obtain these data, 201 st instar larvae were released onto $25 \mathrm{~mm}$ diameter leaf discs from the different brassicas, with 6 replicates for both glasshouse- and field-grown brassicas conducted at the same time.

Emerged pairs of moths were mated, but not all matings were successful. Two fecundity measurements were available for most replicates (when the mean was used for calculating $r_{m}$ ), but sometimes only one.

\subsection{Performance of DBM on the different brassicas on artificial diet with leaf powder}

An artificial diet was prepared as described by Hou (1986) with 2\% agar as the base and brassica leaf powder at 3\% concentration. Fully expanded leaves were removed from the middle region of the different brassicas grown in the glasshouse and the field, placed in plastic zip bags and kept in a freezer at $-20^{\circ} \mathrm{C}$. The leaves were transferred to a freezer freeze drier (Birchover Instruments Ltd., $7.5 \mathrm{l}$ ) for $24 \mathrm{~h}$. The 
freeze-dried leaves were finely ground in an ATO MIX (MSE, London), and incorporated into the artificial diet.

A cube of diet (approximately $5 \mathrm{~g}$ ) was placed in a plastic box and a small slice of Parafilm $\mathrm{M}^{\mathrm{TM}}$, on which the larvae were released, was placed over part of it. The Parafilm prevented the small neonate larvae from becoming stuck in the agar; once they reached the 2 nd instar they could move safely over the moist diet. Fifteen 1 st instar larvae ( $<12 \mathrm{~h}$ old) were placed onto the Parafilm with a fine camel hair brush. All the larvae used were obtained from a culture established on diet incorporating glasshouse-grown CHC leaf powder. The diet was checked every $24 \mathrm{~h}$ and fresh diet was provided as necessary. There were 5 replicates per brassica per growing environment of the plants. The observations that were taken for DBM performance on leaf discs were also recorded on artificial diet.

\subsection{Leaf toughness}

A penetrometer based on the original design of Williams (1954) was constructed. The principle is that the weight of sand required to force a dissecting pin to penetrate the leaf is related to leaf toughness. Observations were taken at 5 different haphazardly chosen places on an individual leaf, and the mean of these 5 measurements was taken as the replicate datum. There were 5 replicates per brassica per growing environment.

\subsection{Extraction of leaf surface wax}

Four replicates of two or three fully expanded leaves from the middle whorl of plants were chosen per treatment for wax extraction. Aluminium foil was cut to the shape of 
a $140 \mathrm{~mm}$ diameter Petri dish and weighed on a balance. $50 \mathrm{ml}$ of dichloromethane was poured into the foil and the whole leaf was gently shaken in this solvent for 20 seconds, making sure that both the upper and the lower surfaces of the leaf were completely immersed. However, care was taken not to immerse the cut end of the petiole. The solvent along with the foil was left in a fume cupboard for $24 \mathrm{~h}$ to evaporate the solvent completely and then the foil along with the extracted wax was weighed. The amount of wax was calculated by subtracting the initial weight of the foil from the final weight after evaporation of the solvent. The surface area of the leaf was measured by a leaf area meter ( $\Delta \mathrm{T}$ Area Meter MK2, Hitachi Ltd.) so that wax could be expressed as $\mu \mathrm{g} \mathrm{cm}^{-2}$ of leaf.

\subsection{Glucosinolate analysis}

Glucosinolates were extracted from freeze dried leaf powder and quantified at the School of Biosciences, University of Nottingham, UK. There were four replicates of each treatment, representing four samples of each brassica leaf powder. The extraction procedure involves conversion of glucosinolates in the freeze-dried leaf powder to desulphoglucosinolates and then eluting these from an ion exchange column (Heaney et al. 1986). The desulphoglucosinolates (DSGSLs) were separated on a reverse phase HPLC column (Spherisorb $5 \mu$ ODS2 250 x $4.6 \mathrm{~mm}$ cartridge, Anachem) using an acetonitrile and water gradient. The DSGSLs were detected by their absorption at 229 $\mathrm{nm}$ and identified with reference to standards identified in Heaney et al. (1986). Quantification was through comparison with the internal standard, using the response factors published by Heaney et al. (1986). 


\subsection{Analysis of data}

Following analysis of variance, differences between means were validated by the LSD test for sources of variation that gave a statistically significant $(\mathrm{P}<0.05)$ variance ratio in the analysis. Unless otherwise stated, all statements made about the results satisfy this probability criterion. The results on leaf discs and artificial diet were analysed independently, as these two experiments were conducted at different times though under broadly similar environmental conditions. More validity can therefore be attached to the comparative rank order of means in the two experiments than to their absolute value. For fecundity data, each measurement obtained was treated as a replicate. This (see 2.4) resulted in unequal replication, and a statistical package allowing for this was used.

The data are presented as tables rather than histograms, since no interactions between the two main factors (brassica and growing environment) were found. Tabular presentation shows more clearly which means are being compared with which LSD.

\section{Results}

For all measures of performance, there were no interactions between brassica and growing environment; therefore the main effects can be interpreted with validity.

\subsection{Performance of DBM on the different brassicas on leaf discs and on artificial diet}


On leaf discs, larval weight after five days was highest on $\mathrm{CHC}$, followed by RDH and OC (not statistically separable) with larvae on MIN showing the lowest weight.

When growing environments were compared, DBM performed better on leaf discs of glasshouse-grown plants than on leaf discs of field-grown ones (Table I).

[Insert Table I about here]

Quite opposite results were observed when the larvae fed on artificial diet. MIN, the least suitable brassica on the basis of larval weight on leaf discs, was the most suitable on the artificial diet and was significantly more so than $\mathrm{CHC}$. $\mathrm{RDH}$, the B. oleracea cultivar on which larvae gained most weight on leaf discs, was the least suitable of all the brassicas, and could not be statistically separated from CHC. The results on OC were intermediate between and overlapped statistically with those on MIN and CHC.

On artificial diet the effect of growing environments was consistent with their effect on leaf discs. DBM again performed better with incorporation of leaf material of glasshouse-grown plants than of field-grown ones (Table I).

The results for larval duration followed the same pattern of substrate suitability as those for larval weight, except for small variations in where statistical overlap occurred between the brassicas with intermediate suitability. Thus on leaf discs larvae on $\mathrm{CHC}$ and MIN showed respectively the shortest and longest development, while on artificial diet larval duration on MIN was significantly shorter than that on CHC. As with the results on weight, discs and artificial diet of glasshouse-grown plants were more suitable than those of field-grown ones, with larvae developing in a shorter time (Table II). 
[Insert Table II about here]

Per cent larval survival to five days varied less with brassica and growing condition than did larval weight and duration, but survival was clearly poorer on artificial diet (where no significant differences in survival were found between the brassicas) than on leaf discs. Consistent with the results on larval weight and duration, survival on leaf discs on MIN was lower than on discs of $\mathrm{CHC}$. However, no difference was found in the survival of larvae on leaf discs of glasshouse-grown and field-grown plants, and the superior suitability for DBM of the former was only shown in the results on artificial diet (Table III).

[Insert Table III about here]

Very few moths reared on artificial diet with leaf powder of RDH emerged, and data for this brassica were not included in the analyses of fecundity and $r_{m}$ on artificial diet.

No significant differences in fecundity were apparent in the results on artificial diet, though means were consistently higher for all brassicas with leaf powder from glasshouse- than field-grown plants and with both environments the mean fecundity for MIN was numerically higher than that for $\mathrm{CHC}$. With leaf discs, where larval duration was longer on field-grown plants, fecundity was now significantly higher on discs from such plants. However, this was the only result on leaf discs that contradicted earlier rankings with larval weight and duration. DBM reared on CHC and MIN (not statistically different from RDH and OC) had respectively the highest 
and lowest fecundities. Fecundity with RDH and OC was again intermediate (Table IV).

[Insert Table IV about here]

Shorter larval duration, higher survival and fecundity produced an $r_{m}$ on leaf discs on CHC higher than that on MIN. The latter overlapped with the still lower $r_{m}$ on OC (with numerically even lower fecundity than on MIN).

On leaf discs of glasshouse-grown plants, the lower fecundity than on fieldgrown plants cancelled out the shorter larval duration to give similar $r_{m}$ values for both environments, whereas on artificial diet the general greater suitability of glasshouse-grown plants was still shown (Table V). However, the $r_{m}$ values for DBM on the different brassicas could not be statistically separated.

[Insert Table V about here]

\subsection{Leaf toughness}

There was no significant interaction between brassicas and growing environments in respect of leaf toughness. All the brassicas were statistically separable, largely due to the values from field-grown plants which were more than twice those of plants grown in the glasshouse. Leaves of RDH were the toughest followed by MIN and then OC. Leaves of CHC were the least tough with the weight of sand needed for the needle to penetrate the leaf only about half of that needed with the other brassicas (Table VI). 
[Insert Table VI about here]

\subsection{Amount of surface wax}

The wax of CHC was so little as to be below the detection threshold of the analytical method used, and this brassica was excluded from the statistical analysis. There was no significant interaction between brassicas and growing environments. There were no significant differences in the amount of leaf surface wax between the brassicas included in the analysis, but field-grown brassicas had significantly higher amounts than glasshouse-grown plants (Table VII).

[Insert Table VII about here]

\subsection{Concentration of glucosinolates}

With no interactions between brassicas and growing environments in the concentration of glucosinolates in the leaves, the two sources of variation are presented in separate tables. The pattern of inter-brassica differences showed no consistency between the different glucosinolates (Table VIII). However, the field-

[Insert Table VII about here]

grown brassicas consistently showed significantly higher concentrations than the glasshouse-grown plants with all the glucosinolates (significantly so except for 1methoxy indolylmethyl) (Table IX). 
[Insert Table IX about here]

\section{Discussion}

On leaf discs, based on larval weights, larval duration, per cent larvae surviving to five days, fecundity of the adults and $r_{m}, \mathrm{CHC}$ and MIN were respectively the best and least suitable hosts for DBM, with $\mathrm{RDH}$ and $\mathrm{OC}$ as intermediate with respect to DBM performance.

On artificial diet, however, with any physical differences largely removed, the rankings reversed and DBM performance (in all the criteria measured) was worst where CHC leaf powder had been incorporated. The only exception was that the longest larval duration on diet was found with field-grown RDH. Again in contrast to DBM performance on leaf discs, MIN provided the best substrate of the diets.

These results suggest that the observed partial resistance to DBM of MIN on leaf discs was due to physical rather than chemical factors. However, artificial diet did not remove differences between brassicas in larval weight and duration. Differences remained evident on artificial diet, and moreover they were often the reverse of the results on leaf discs. Thus on leaf discs, physical factors appeared to have masked the effect of chemical factors which intrinsically favoured MIN in terms of DBM performance.

The poor performance of DBM on diet incorporating field-grown RDH leaf powder could after all have been due to the toughness of the leaves, since field-grown RDH had the toughest leaves and thickest leaf veins of all the brassicas tested. Even after freeze-drying and milling, the resulting powder would still have had a higher leaf vein:leaf lamina ratio than powders of the other brassicas. 
However, red cabbages like RDH are rich sources of anthocyanin pigments, and both mono and diacylated cyaniding derivatives of anthocyanins have been identified in red cabbage (Idaka et al. 1987a,b). Harborne (1988) reported that anthocyanins and other plant flavonoids confer resistance to insects. Cyanidin 3glucoside in cotton leaves has been shown to protect the leaves from feeding by the tobacco budworm Heliothis virescens F. (Lepidoptera: Noctuidae) (Hedin et al. 1983). If the artificial diet results reflect the effect of chemical factors more closely than do the results on leaf discs (where suitability for DBM can be determined by physical factors), then the glucosinolate profiles would indicate that, in general, increasing the concentration of individual glucosinolates had a positive effect on DBM. This is perhaps because glucosinolates act as phagostimulants for the pest. The role of glucosinolates in insect-plant relationships, including their function as oviposition and feeding stimulants for more than 25 crucifer-specialist insects, including P. xylostella, has recently been reviewed by Hopkins et al. (2009). However, different glucosinolate compounds affect different herbivores in different ways and Poelman et al. (2008) were unable to explain the performance of a specialist and generalist caterpillar on a range of brassica cultivars from the overall concentration of glucosinolates. In our study, six out of seven individual glucosinolates were detected in MIN, RDH and OC whereas only four were detected in CHC. Also sinigrin (a well-known important phagostimulant for crucifer specialist insects), was found in a high concentration in brassicae MIN $\left(1.758 \mu \mathrm{mol} \mathrm{g}^{-1} \mathrm{dry}\right.$ wt of sample) but could not be detected in CHC. The reverse result of the suitability of CHC leaf material relative to that of MIN would seem to emphasise the role of the low toughness and low wax load of $\mathrm{CHC}$ dominating over the spectrum of phagostimulants. 
All the brassicas had tougher leaves and more surface wax when grown under field conditions than when grown in the glasshouse. That DBM performed better on glasshouse-grown brassicas both on leaf discs and artificial diet (except for the very low value of $r_{m}$ for OC on glasshouse grown leaf discs) may have been due to the fact that field-grown brassicas had tougher leaves (twice the toughness of glasshousegrown plants) as well as more surface wax. When these leaves were milled, the resulting powder would still have contained the wax (though distributed more dilutely) and would have had more leaf vein tissues and wax that contributed to the poor performance of DBM

Thus the separation of chemical and physical factors by using artificial diet (Berdegue and Trumble 1996) appears far from complete. Even so, the leaf disc and artificial diet studies revealed that the mechanism of differential susceptibility to DMB in the brassicas investigated here was mainly physical or mechanical. Leaf tissue hardness is known as a common general defence of plants against insect herbivores (van Emden and Way 1972, Verkerk 1995).

Glucosinolates mainly increased the suitability of plants for DBM. The activity of glucosinolates and their breakdown products as phagostimulants, attractants and cues for crucifer-specialist insects and their parasitoids has been established by many workers (Thorsteinson 1953, Reed et al. 1995, Vaughn et al. 1996, Murchie et al. 1997, Isidoro et al. 1998, Renwick and Lopez 1999, Poelman et al. 2008, Hopkins et al. 2009).

\section{Acknowledgement}


We are most grateful to Professor Richard Mithen, now at the Food Research Institute in Norwich, for generously providing training and facilities for glucosinolate analyses at the University of Nottingham, Sutton Bonington campus.

\section{References}

Abro GH, Wright DJ. 1989. Host plant preference and the influence of different cabbage cultivars on the toxicity of abamectin and cypermethrin against Plutella xylostella Lepidoptera: Plutellidae. Annals of Applied Biology 115: 481-487.

Berdegue M, Trumble JT. 1996. Effects of plant chemical extracts and physical characteristics of Apium graveolens and Chenopodium murale on host choice by Spodoptera exigua larvae. Entomologia Experimentalis et Applicata 78: 253-262.

Dickson MH, Eckenrode CJ. 1975. Variation in Brassica oleracea resistance to cabbage looper and imported cabbage worm in the greenhouse and field. Journal of Economic Entomology 68: 757-760.

Dickson MH, Eckenrode CJ. 1980. Breeding for resistance in cabbage and cauliflower to cabbage looper, imported cabbage worm and diamondback moth. Journal of the American Society for Horticultural Science 105: 782-785.

Eigenbrode SD, Shelton AM. 1990. Resistances to diamondback moth in Brassica: mechanisms and potential for resistant cultivars. In: Talekar N, editor. Proceedings of the second international workshop on diamondback moth and other crucifer pests, Tainan, 10-14 December 1990. Shanhua, Taiwan: Asian Vegetable Research and Development Centre. p 65-74.

Eigenbrode SD, Stoner KA, Shelton AM, Kain WC. 1991. Characteristics of glossy leaf waxes associated with resistance to diamondback moth (Lepidoptera: 
Plutellidae) in Brassica oleracea. Journal of Economic Entomology 84: 16091618.

van Emden HF, Way MJ 1972. Host plants in the population dynamics of insects. In: van Emden HF, editor. Insect/Plant Relationships. Oxford: Blackwell. p 181-199.

Harborne JB 1988. Introduction to Ecological Biochemistry, 3rd edition. London: Academic Press. p 147-185.

Heaney RK, Spinks AB, Hanley AB, Fenwick GR. 1986. Analysis of glucosinolates in rapeseed. Technical bulletin. Norwich: AFRC Food Research Institute.

Hedin PA, Jenkins JN, Collum DH, White WH, Parrott WL. 1983. Multiple factors in cotton contributing to resistance to the tobacco budworm, Heliothis virescens F. In: Hedin PA, editor. Plant Resistance to Insects. Washington, DC: American Chemical Society. p 347-365.

Hopkins RF, van Dam NM, van Loon JJA. 2009. Role of glucosinolates in insectplant relationships and multitrophic interactions. Annual Review of Entomology 54: $57-83$

Hou RF. 1986. Mass rearing of diamondback moth. In: Talekar NS, Griggs TD, editors. Proceedings of the first international workshop on diamondback moth management Tainan, 11-15 March 1985. Shanhua, Taiwan: Asian Vegetable Research and Development Centre. p 89-95.

Idaka E, Suzuki K, Yamakita H, Ogawa T, Kondo T, Goto T. 1987a. Structure of monoacylated anthocyanins isolated from red cabbage, Brassica oleracea. Chemistry Letters 1: 145-148.

Idaka E, Yamakita H, Ogawa T, Kondo T, Yamamoto M, Goto T. 1987b. Structure of three diacylated anthocyanins isolated from red cabbage, Brassica oleracea. Chemistry Letters 6: 1213-1216. 
Isidoro N, Bartlet E, Ziesmann J, Williams IH. 1998. Antennal contact chemosensilla in Psylliodes chrysocephala responding to cruciferous allelochemicals.

Physiological Entomology 23: 131-138.

Janmaat AF. 2007. Development of resistance to the biopesticide Bacillus thuringiensis kurstaki. In: Biological control: a global perpective (Vincent C, Goettel MS, Lazarovits G, editors. Wallingford: CABI. p 179-184.

Lin J, Dickson MH, Eckenrode CJ. 1984. Resistance of Brassica lines to the diamondback moth (Lepidoptera: Yponomeutidae) in the field, and inheritance of resistance. Journal of Economic Entomology 77: 1293-1296.

Lin J, Eckenrode CJ, Dickson MH. 1983. Variation in Brassica oleracea resistance to diamondback moth (Lepidoptera: Plutellidae). Journal of Economic Entomology 76: $1423-1427$

MAFF 1994. Fertilizer recommendations for agricultural and horticultural crops. Ministry of Agriculture Fisheries and Food reference book 209, 6th Edition. London: The Stationery Office.

Murchie AK, Smart LE, Williams IH. 1997. Responses of Dasineura brassicae and its parasitoids Platygaster subuliformis and Omphale clypealis to field traps baited with organic isothiocyanates. Journal of Chemical Ecology 23: 917-926.

Poelman EH, Galiart RJFH, Raaijmakers CE, van Loon JJA, van Dam NM. 2008. Performance of specialist and generalist herbivores feeding on cabbage cultivars is not explained by glucosinolate profiles. Entomologia Experimentalis et Applicata 127: $218-228$.

Reed HC, Tan SH, Haapenen K, Killmon M, Reed DK, Elliot NC. 1995. 
Olfactory responses of the parasitoid Diarietiella rapae (Hymenoptera:Aphididae) to odour of plants, aphids and plant-aphid complexes. Journal of Chemical Ecology 21: 407-418.

Renwick JAA, Lopez K. 1999. Experience-based food consumption by larvae of Pieris rapae: addiction to glucosinolates. In: Simpson SJ, Mordue AJ, Hardie J, editors. Proceedings of the 10th international symposium on insect-plant relationships, Oxford, 4-10 July 1998. Dordrecht, The Netherlands: Kluwer. p 5158.

Rudder JD, Brett CH. 1967. Resistance of commercial cruciferous varieties to larvae of the diamondback moth in the coastal plains of North Carolina. Journal of Economic Entomology 60: 1272-1275.

Schuler TH, van Emden HF. 2000. Resistant cabbage cultivars change the susceptibility of Plutella xylostella to Bacillus thuringiensis. Agricultural and Forest Entomology 2: 33-38.

Stoner KA. 1990. Glossy leaf wax and plant resistance to insects in Brassica oleracea under natural infestation. Environmental Entomology 19: 730-739.

Tabashnik BE, Cushing NL, Finson N, Johnson MW. 1990. Field development of resistance to Bacillus thuringiensis in diamondback moth (Lepidoptera: Plutellidae). Journal of Economic Entomology 83: 1671-1676.

Thorsteinson AJ. 1953. The chemotactic responses that determine host specificity in an oligophagous insect (Plutella maculipennis (Curt.) Lepidoptera). Canadian Journal of Zoology 31: 52-71.

Vaughn TT, Antolin MF, Bjostad LB. 1996. Behavioural and physiochemical responses of Diaeretiella rapae to semiochemicals. Entomologia Experimentalis et Applicata 78: 187-196. 
Verkerk RHJ. 1995. Studies on interactions between diamondback moth, host plants, endolarval parasitoids and selective toxicants. $\mathrm{PhD}$ thesis, University of London.

Verkerk RHJ, Wright DJ. 1994. Interactions between the diamondback moth, Plutella xylostella (L.) and glasshouse and out-door grown cabbage cultivars. Annals of Applied Biology 125: 477-488.

Verkerk RHJ, Wright DJ. 1996a. Common cabbage resistance mechanisms against the diamondback moth: still an open book? Annals of Applied Biology 128: 571577.

Verkerk RHJ, Wright DJ. 1996b. Multitrophic interactions and management of diamondback moth: a review. Bulletin of Entomological Research 86: 205-216.

Williams LH. (1954). The feeding habits and food preferences of Acrididae and the factors which determine them. Transactions of the Royal Entomological Society, London 105: 423-454. 
Table I. Weight (mg) of DBM larvae reared on leaf discs (initially 20 larvae per replicate) and on artificial diet (initially 15 larvae per replicate) after 5 days.

\begin{tabular}{llllllll}
\hline & CHC & RDH & OC & MIN & Mean & LSD \\
\hline On leaf discs & Glasshouse & 5.48 & 4.56 & 4.01 & 3.83 & $4.47^{\mathrm{a}}$ & 0.44 \\
$(\mathrm{n}=6)$ & Field & 4.80 & 3.96 & 4.17 & 2.45 & $3.83^{\mathrm{b}}$ & \\
& Mean & $5.14^{\mathrm{a}}$ & $4.23^{\mathrm{b}}$ & $4.09^{\mathrm{b}}$ & $3.14^{\mathrm{c}}$ & & 0.62 \\
& & & & & & \\
On artificial diet & Glasshouse & 0.538 & $0.612^{2}$ & 0.696 & 0.782 & $0.657^{\mathrm{a}}$ & 0.098 \\
$(\mathrm{n}=5)$ & Field & 0.397 & $0.238^{2}$ & 0.498 & 0.618 & $0.438^{\mathrm{b}}$ & \\
& Mean & $0.467^{\mathrm{bc}}$ & $0.425^{\mathrm{c}}$ & $0.597^{\mathrm{ab}}$ & $0.700^{\mathrm{a}}$ & & 0.139 \\
\hline
\end{tabular}

There were no significant interactions between brassicas and growing environments.

Means for each main factor followed by the same letters are not significantly different at $\mathrm{P}=0.05$. 
Table II. DBM larval duration (days) on leaf discs (initially 20 larvae per replicate) and on artificial diet (initially 15 larvae per replicate).

\begin{tabular}{|c|c|c|c|c|c|c|c|}
\hline & & $\mathrm{CHC}$ & $\mathrm{RDH}$ & $\mathrm{OC}$ & MIN & Mean & LSD \\
\hline On leaf discs & Glasshouse & 6.33 & 6.79 & 6.84 & 7.00 & $6.74^{b}$ & 0.13 \\
\hline \multirow[t]{2}{*}{$(n=6)$} & Field & 7.46 & 7.72 & 7.74 & 8.10 & $7.75^{\mathrm{a}}$ & \\
\hline & Mean & $6.89^{c}$ & $7.25^{b}$ & $7.29^{b}$ & $7.55^{\mathrm{a}}$ & & 0.19 \\
\hline \multirow{3}{*}{$\begin{array}{l}\text { On artificial diet } \\
(n=5)\end{array}$} & Glasshouse & 9.58 & 9.96 & 9.20 & 9.04 & $9.44^{b}$ & 0.39 \\
\hline & Field & 10.07 & 14.99 & 10.00 & 9.40 & $11.11^{\mathrm{a}}$ & \\
\hline & Mean & $9.82^{b}$ & $12.47^{\mathrm{a}}$ & $9.60^{b c}$ & $9.20^{c}$ & & 0.55 \\
\hline
\end{tabular}

There were no significant interactions between brassicas and growing environments.

Means for each main factor followed by the same letters are not significantly different at $\mathrm{P}=0.05$. 
Table III. Per cent surviving larvae (after 5 days) on leaf disc (initially 20 larvae per replicate and on artificial diet (initially 15 larvae per replicate).

\begin{tabular}{|c|c|c|c|c|c|c|c|}
\hline & & $\mathrm{CHC}$ & RDH & $\mathrm{OC}$ & MIN & Mean & LSD \\
\hline On leaf discs & Glasshouse & 93.3 & 89.2 & 85.8 & 85.0 & $88.3^{a}$ & 3.9 \\
\hline \multirow[t]{2}{*}{$(n=6)$} & Field & 89.2 & 93.3 & 89.2 & 83.3 & $88.7^{\mathrm{a}}$ & \\
\hline & Mean & $91.2^{\mathrm{a}}$ & $91.2^{\mathrm{a}}$ & $87.5^{\mathrm{ab}}$ & $84.1^{\mathrm{a}}$ & & 5.5 \\
\hline On artificial diet & Glasshouse & 92.0 & 69.3 & 78.7 & 72.0 & $78.0^{\mathrm{a}}$ & 10.3 \\
\hline \multirow[t]{2}{*}{$(\mathrm{n}=5)$} & Field & 65.3 & 63.2 & 74.2 & 64.0 & $66.7^{b}$ & \\
\hline & Mean & $78.7^{\mathrm{a}}$ & $66.3^{a}$ & $76.5^{\mathrm{a}}$ & $68.0^{\mathrm{a}}$ & & 14.6 \\
\hline
\end{tabular}

There were no significant interactions between brassicas and growing environments.

Means for each main factor followed by the same letters are not significantly different at $\mathrm{P}=0.05$. 
Table IV. Fecundity of DBM on leaf discs and on artificial diet (n varied between 4 and 10).

\begin{tabular}{llrrrrrr}
\hline & & CHC & RDH & OC & MIN & Mean & LSD \\
\hline On leaf discs & Glasshouse & 83.4 & 69.1 & 53.1 & 66.0 & $67.9^{\mathrm{b}}$ & 11.7 \\
& Field & 117.6 & 111.9 & 94.4 & 101.6 & $106.4^{\mathrm{a}}$ & \\
& Mean & $100.5^{\mathrm{a}}$ & $90.5^{\mathrm{ab}}$ & $73.8^{\mathrm{b}}$ & $83.8^{\mathrm{b}}$ & & 16.7 \\
\hline \multirow{2}{*}{ On artificial diet } & Glasshouse & 55.1 & - & 64.4 & 71.4 & $63.0^{\mathrm{a}}$ & 27.3 \\
& Field & 48.1 & - & 64.1 & 50.3 & $54.1^{\mathrm{a}}$ & \\
& Mean & $51.6^{\mathrm{a}}$ & - & $64.2^{\mathrm{a}}$ & $60.8^{\mathrm{a}}$ & & 17.9 \\
& & & & & & & \\
\end{tabular}

There were no significant interactions between brassicas and growing environments.

Means for each main factor followed by the same letters are not significantly different at $\mathrm{P}=0.05$. 
Table V. Intrinsic rate of population increase $\left(r_{m}\right)$ of DBM on leaf discs and on artificial diet (combining means for replicates from Tables II - IV).

\begin{tabular}{llllllll}
\hline & & CHC & RDH & OC & MIN & Mean & LSD \\
\hline On leaf discs & Glasshouse & 0.3539 & 0.3135 & 0.2852 & 0.3166 & $0.3173^{\mathrm{a}}$ & 0.0176 \\
$(\mathrm{n}=6)$ & Field & 0.3597 & 0.3364 & 0.3227 & 0.3211 & $0.3350^{\mathrm{a}}$ & \\
& Mean & $0.3568^{\mathrm{a}}$ & $0.3249^{\mathrm{b}}$ & $0.3039^{\mathrm{b}}$ & $0.3188^{\mathrm{b}}$ & & 0.0248 \\
\hline On artificial diet & Glasshouse & 0.2443 & - & 0.2432 & 0.2385 & $0.2420^{\mathrm{a}}$ & 0.0272 \\
$(\mathrm{n}=5)$ & Field & 0.2008 & - & 0.2051 & 0.2038 & $0.2033^{\mathrm{b}}$ & \\
& Mean & $0.2226^{\mathrm{a}}$ & - & $0.2241^{\mathrm{a}}$ & $0.2212^{\mathrm{a}}$ & & 0.0333 \\
\hline
\end{tabular}

There were no significant interactions between brassicas and growing environments.

Means for each main factor followed by the same letters are not significantly different at $\mathrm{P}=0.05$. 
Table VI. Weight of sand $(\mathrm{g})$ required to cause penetration of leaves $(\mathrm{n}=5$, each a mean of 5 data).

\begin{tabular}{lllll}
\hline Brassica & Glasshouse & Field & Mean & LSD \\
\hline CHC & 7.90 & 11.53 & $9.71^{\mathrm{d}}$ & 1.29 \\
RDH & 9.89 & 36.94 & $23.42^{\mathrm{a}}$ & \\
OC & 9.70 & 27.68 & $18.69^{\mathrm{c}}$ & \\
MIN & 13.22 & 31.01 & $22.11^{\mathrm{b}}$ & \\
Mean & $10.18^{\mathrm{b}}$ & $26.79^{\mathrm{a}}$ & & 0.91 \\
\hline
\end{tabular}

There was no significant interaction between brassicas and growing environments.

Means for each main factor followed by the same letters are not significantly different at $\mathrm{P}=0.05$ 
Table VII. Amount of surface wax $\left(\mu \mathrm{g} / \mathrm{cm}^{2}\right)$ from leaves of different brassicas $(\mathrm{n}=$ $10)$.

\begin{tabular}{lllll}
\hline Brassica & Glasshouse & Field & Mean & LSD \\
\hline CHC & - & - & - & - \\
RDH & 113.3 & 186.6 & $150.0^{\mathrm{a}}$ & 33.7 \\
OC & 97.1 & 141.7 & $119.4^{\mathrm{a}}$ & \\
MIN & $141.8^{\mathrm{a}}$ & 160.3 & $151.1^{\mathrm{a}}$ & \\
\hline Mean & $117.4^{\mathrm{b}}$ & $162.9^{\mathrm{a}}$ & & 27.5 \\
\hline
\end{tabular}

There was no significant interaction between brassicas and growing environments.

Means for each main factor followed by the same letters are not significantly different at $\mathrm{P}=0.05$ 
Table VIII. Rankings of concentrations $(\mu \mathrm{mol} / \mathrm{g}$ dry wt. of sample $(\mathrm{n}=4)$ ) of the different glucosinolates where identified in the different brassicas. <, significant increase.

\begin{tabular}{lll}
\hline Glucosinolate & Rankings & $\begin{array}{c}\text { LSD } \\
(\mathrm{P}=0.05)\end{array}$ \\
\hline 1-Methoxy indolylmethyl & $\mathrm{RDH}(0.231)=\mathrm{OC}(0.239)=\mathrm{MIN}(0.356)<\mathrm{CHC}(1.894)$ & 0.336 \\
4-Methoxy indolylmethyl & $\mathrm{MIN}(0.200)=\mathrm{RDH}(0.327)=\mathrm{OC}(0.376)<\mathrm{CHC}(0.692)$ & 0.347 \\
3-Butenyl & $\mathrm{CHC}(0.637)$ & - \\
4-Methyl sulfinyl butyl & $\mathrm{MIN}(0.449)=\mathrm{OC}(0.527)<\mathrm{RDH}(1.603)$ & 0.196 \\
3-Methyl sulfinyl propyl & $\mathrm{MIN}(0.321)<\mathrm{OC}(0.380)<\mathrm{RDH}(0.429)$ & 0.033 \\
3-Indolmethyl & $\mathrm{CHC}(0.67)<\mathrm{MIN}(5.02)=\mathrm{RDH}(5.37)<\mathrm{OC}(7.16)$ & 0.67 \\
Sinigrin & $\mathrm{RDH}(0.677)<\mathrm{OC}(1.655)=\mathrm{MIN}(1.758)$ & 0.201 \\
\hline
\end{tabular}


Table IX. Rankings of concentrations ( $\mu \mathrm{mol} / \mathrm{g}$ dry wt. of sample $(\mathrm{n}=4)$ ) of the different glucosinolates in plants grown in the glasshouse (GLH) or the field (FLD). $<$, significant increase.

\begin{tabular}{lll}
\hline Glucosinolate & Ranking & LSD (P=0.05) \\
\hline 1-methoxy indolylmethyl & $\mathrm{GLH}(0.623)=\mathrm{FLD}(0.737)$ & 0.237 \\
4-methoxy indolylmethyl & $\mathrm{GLH}(0.154)<\mathrm{FLD}(0.643)$ & 0.245 \\
3-butenyl & $\mathrm{GLH}(0.272)<\mathrm{FLD}(1.002)$ & 0.495 \\
4-methyl sulfinyl butyl & $\mathrm{GLH}(0.583)<\mathrm{FLD}(1.136)$ & 0.159 \\
3-methyl sulfinyl propyl & $\mathrm{GLH}(0.287)<\mathrm{FLD}(0.466)$ & 0.027 \\
3-indolmethyl & $\mathrm{GLH}(3.65)<\mathrm{FLD}(5.47)$ & 0.470 \\
sinigrin & $\mathrm{GLH}(1.161)<\mathrm{FLD}(1.565)$ & 0.164 \\
\hline
\end{tabular}

